\title{
Professor Warren Boling: please be passionate about everything you do
}

Submitted Sep 18, 2019. Accepted for publication Sep 26, 2019.

doi: 10.21037/atm.2019.09.149

View this article at: http://dx.doi.org/10.21037/atm.2019.09.149

\section{Editor's note}

On August 17-18, the 1st CIMS International Medical Summit 2019 was successfully held in Beijing, China, focusing on the hot topics of obstetrics, lung cancer, gastrointestinal cancer, proton beam therapy, neurooncology, neurosurgery and etc. During this forum, we are glad to interview Prof. Warren Boling, from Loma Linda University, to share his perspectives on minimally invasive neurosurgery.

\section{Expert's introduction}

Warren Boling (Figure 1) trained in Neurosurgery at the University of Kentucky and then completed fellowships in Epilepsy and Stereotactic Surgery at Montreal Neurological Institute and Austin Repatriation Hospital, University of Melbourne. He joined the faculty at Montreal Neurological Institute where he was a member of the Comprehensive Epilepsy Program. He went on to develop the first comprehensive epilepsy program in West Virginia, at West Virginia University. Through his global outreach, Prof. Boling developed the first surgery for epilepsy program in East Africa. He has been faculty at The University of Melbourne and University of Louisville.

Currently, Prof. Boling is the Chair of the Department of Neurosurgery at Loma Linda University and Chief of Neurosurgery at Loma Linda University Hospital. Additionally, he directs the surgery of epilepsy program at Loma Linda University. Prof. Boling has an interest in improving the lives of people with epilepsy and in elevating the medical and surgical treatment of neurological diseases in underserved regions of the world.

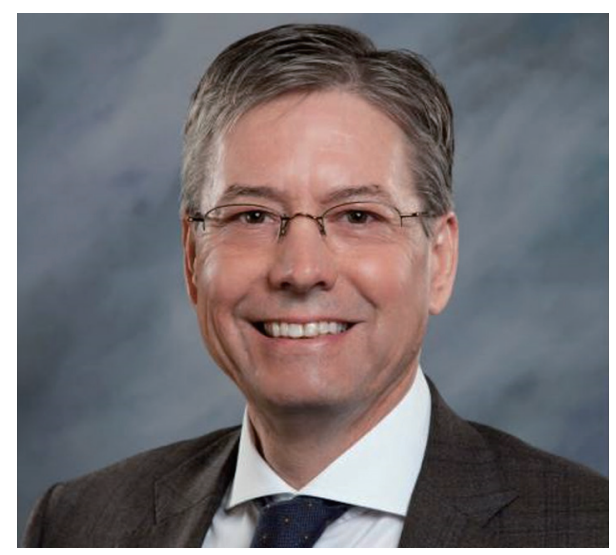

Figure 1 Prof. Warren Boling.

\section{Interview (Figure 2)}

ATM: Minimally invasive neurosurgery is the trend of the times, would you please give us a brief introduction of its status, especially in your department?

Prof. Boling: Minimally invasive neurosurgery is rapidly growing throughout North America and the world. It is ripened by computational advances, advances in imaging. With the guidance of imaging, we can now navigate around the brain and even the spine using computers, and this allows us to make much smaller openings to do major surgeries through with very minimal access into the skin. Increasingly, patients are asking for this. They look up on the internet, hear stories about what the future may bring for surgery, and what is being done; so, more and more patients desire this type of approach. Also, we have done many studies around minimally invasive neurosurgery, and 


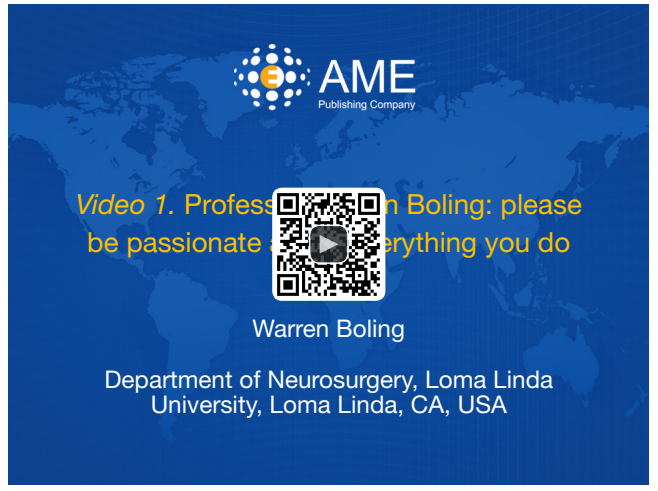

Figure 2 Professor Warren Boling: please be passionate about everything you do (1).

Available online: http://www.asvide.com/watch/33016

we know that patients recover quicker and much happier. So, overall, this is the train that we want to take.

\section{ATM: Could you share with us your prospect of the development of minimally invasive neurosurgery in the coming years?}

Prof. Boling: Yes, and it is growing rapidly. As the imaging gets better, the computers get faster and more powerful, it would be able to perform surgeries through using navigation, even in the magnetic resonance imaging (MRI) scanner. It is another trend and another way to perform neurosurgery within the magnet, within the MRI. These are all driving us to do surgeries, even more, and more minimally and visibly.

\section{ATM: As the chair of the neurosurgery department, could you please share with us the main projects being carried out?}

Prof. Boling: In my department, we have pillar programs around the movement disorder, epilepsy, brain tumor, spine, pediatric brain surgery. And for each of these pillar programs, we have several issues ongoing, much of them are around the minimally invasive approach of surgeries, we are doing it increasingly more surgery inside the MRI magnet, patients are recovering faster and going home sooner, and having fewer complications. This is what the future is bringing us.

\section{ATM: What would be your suggestions for the college} students who are pouring their lives into this field?

Prof. Boling: Most importantly, you must be passionate. If you are passionate about anything, including medicine, then you will find that it is fun to study and work hard. Thus, studying and working hard is a requirement to be successful. So, I would say the first important thing is to find your passion.

ATM: As we know, you have received several distinguished bonors and awards, including "Top Brain Surgeon" in Louisville Magazine, and has published numerous peerreviewed articles, abstracts and book chapters, so bow do you keep passionate in your clinical researches?

Prof. Boling: Primarily, passion is internal, and it comes from the inside, so what I like to do is to enjoy what I am doing. I can get a great deal of personal satisfaction from helping patients and improving the quality of life, and these things keep me going and keeps me passionate about what I do.

\section{ATM: What are your interests outside of medicine?}

Prof. Boling: I enjoy spending time with my family. I like gardening and playing with my son. We always go hiking or play outdoor to enjoy sports and cycling.

\section{Acknowledgments}

We would like to express our sincerest gratitude to Prof. Warren Boling for sharing his insights and opinions with us.

\section{Footnote}

Conflicts of Interest: The authors have no conflicts of interest to declare.

\section{References}

1. Zhang A, Yan C. Professor Warren Boling: please be passionate about everything you do. Asvide 2019;6:331. Available online: http://www.asvide.com/watch/33016 
(Science Editors: Anita Zhang, Crystal Yan, ATM, editor@atmjournal.org)

(Language Editor: Jeremy Chapnick, AME Publishing Company)
Cite this article as: Zhang A, Yan C. Professor Warren Boling: please be passionate about everything you do. Ann Transl Med 2019;7(22):710. doi: 10.21037/atm.2019.09.149 